\title{
Enhancement of learning objectives in construction engineering education: a step towards simulation assessment
}

Conference or Workshop Item

Accepted Version

Castronovo, F., Nikolic, D., Zappe, S., Leicht, R. and Messner, J. (2014) Enhancement of learning objectives in construction engineering education: a step towards simulation assessment. In: Construction Research Congress 2014, 19-21 May 2014, Atlanta, Georgia, pp. 339-348. doi:

https://doi.org/10.1061/9780784413517.035 Available at https://centaur.reading.ac.uk/95014/

It is advisable to refer to the publisher's version if you intend to cite from the work. See Guidance on citing.

To link to this article DOI: http://dx.doi.org/10.1061/9780784413517.035

All outputs in CentAUR are protected by Intellectual Property Rights law, including copyright law. Copyright and IPR is retained by the creators or other copyright holders. Terms and conditions for use of this material are defined in the End User Agreement. 


\section{CentAUR}

Central Archive at the University of Reading

Reading's research outputs online 


\title{
Enhancement of Learning Objectives in Construction Engineering Education: A Step towards Simulation Assessment
}

\author{
Fadi CASTRONOVO ${ }^{1}$, Dragana NIKOLIC ${ }^{2}$, Sarah E. ZAPPE ${ }^{3}$, Robert M. LEICHT $^{4}$, \\ John I. MESSNER ${ }^{5}$
}

${ }^{1}$ Computer Integrated Construction (CIC) Research Program, Department of Architectural Engineering, The Pennsylvania State University, University Park, PA16802; email: fadi@psu.edu

2 School of Construction Management and Engineering, University of Reading, Whiteknights, Reading, UK; email: d.nikolic@reading.ac.uk

${ }^{3}$ College of Engineering, The Leonhard Center for the Enhancement of Engineering Education, The Pennsylvania State University, University Park, PA16802; email: szappe@engr.psu.edu

4 Computer Integrated Construction (CIC) Research Program, Department of Architectural Engineering, The Pennsylvania State University, University Park, PA16802; email: rmleicht @psu.edu

${ }^{5}$ Computer Integrated Construction (CIC) Research Program, Department of Architectural Engineering, The Pennsylvania State University, University Park, PA16802; email: jmessner@psu.edu

\begin{abstract}
The growing use of digital technology in design and construction has brought a change in teaching dynamics. For example, serious games have shown great potential in enhancing the learning of dynamic construction concepts traditionally acquired through practical experience. One such example is the Virtual Construction Simulator 3 (VCS3) game, developed and implemented to engage students in an active learning environment by simulating the planning and managing of a construction project. Initial assessment of the VCS game has demonstrated benefits for both students' motivation and basic understanding of construction concepts. However, further assessment is required in order to demonstrate the benefits on higher order cognitive skills. This paper introduces the first step, the formulation of learning objectives for higher order cognitive skills in construction simulation gaming. Learning objectives from third and fourth year construction engineering courses, together with the previous VCS learning objectives, are analyzed and categorized. The learning objectives guiding the next phase of the VCS4 simulation game development are then presented from a lower- to a higher level thinking skills. This initial step opens the next phase in the development and assessment of the VCS4.
\end{abstract}

\section{TECHNOLOGY DRIVEN LEARNERS}

For students in construction and architectural engineering, analytical skills along with abilities to solve problems, visualize, and make decisions are critical (Alias et al. 2002; Kosslyn 1994). The advancements of information technology in the architecture, engineering, and construction (AEC) industry have challenged academia to adequately prepare students for the changing environment ( $\mathrm{Wu}$ and Issa 
2013). Building information modeling (BIM) has also started to become an integral component in most architectural and civil engineering departments (Wu and Issa 2013). Moreover, the profusion of digital technology in the past decades has brought a new generation of engineering students. This new "Millennial" generation prefers to collaborate, extensively use technology, and work in team based experiential activities (Frand 2000; Jonas-Dwyer and Pospisil 2004; Nguyen et al. 2010; Oblinger 2003; Prensky 2001). In construction education, field-based experiential learning allows students to experiment and acquire knowledge they can apply for solving real construction problems. Experiential learning has thus been suggested as a valid learning method, which adequately prepares engineering students for industry problem solving (Tener et al. 2001).

Currently, the traditional lecture based classroom is limited in offering the students experiential learning activities, as compared to a summer internship, for example. Traditional instruction typically presents the students with well-defined and fragmented construction problems, which do not prepare them with proper decision making skills (Lattuca et al. 2006; Mukherjee et al. 2005). On the other hand, while facilitating the design and construction process, standard BIM and CAD applications are not developed as experiential learning platforms, and often require a level of existing construction and design knowledge. The instructor focused nature of traditional teaching approaches thus remain limited in providing students with the necessary experience to prepare them for the professional world (Nikolic et al. 2010).

Educational serious games have shown great promise in their ability to provide students with an experiential learning environment and also match different learning styles. Computer simulations and games are being increasingly explored for their ability to support learning by providing a close to realistic environment for problem solving through visualization, exploration, and immediate feedback (Gee 2007; Ke 2009). In a recent effort, the Computer Integrated Construction (CIC) Research Program introduced an experiential learning into the classroom by developing and evaluating the Virtual Construction Simulator 3 (VCS3), a construction simulation game. Based on the findings, the next development phase will expand the VCS4 game with a new user interface and the assessment framework. With an emphasis on evaluating higher order learning, this research stage focuses on creating a set of the VCS learning objectives guiding the game development and assessment to further an understanding of the measurable impact of simulation games on learning.

\section{LEARNING OBJECTIVES IN SIMULATION GAMING: A FIRST STEP TORWARD ASSESSMENT}

Simulation games target multiple levels of the learning process. Learning is a complex and multidimensional construct, and composed of a cognitive, metacognitive, and motivational component (Mayer 1998). Simulation games have demonstrated to increase the learners' motivation due to their ability to challenge, promote curiosity, and provide immediate feedback (Malone 1981). However, even though simulation games have been acclaimed for their benefits as instructional tools, they are yet to receive broader acceptance in academic curricula. The reason for such state is, in part, because of the lack of convincing data in their learning effectiveness 
(Nikolic and Messner 2012). O’Neil et al. (2005) notes a general sentiment that simulation games mainly entertain the learner, while losing the educational aspect of the exercise. This lack of convincing educational benefits of simulation games can thus cause their dismissal as "motivational fluff” (O’Neil et al. 2005). Therefore, a broader adoption of educational simulation games greatly depends on the rigorous assessment of the learning benefits.

However, the progress in simulation evaluation has been gradual. This slow acceptance can be linked to the challenges in conducting experimental studies, and the inherent challenges in creating an adequate methodology of assessment (Feinstein and Cannon 2002). Several challenges have been identified in evaluating the effectiveness of simulation games, including the lack of an agreed definition of simulation games (Burns et al. 1990); time constraints for developing a valid instrument; and the use of non-indicative metrics for learning such as game performance, level of success or achieving a correct solution (Gosen and Washbush 2004). Simulation games have largely resulted in learners' enjoyment, attitude change, and tolerance for ambiguity (Warren 2001). Still, as Warren (2001) notices, these benefits remain irrelevant in traditional learning evaluation which mainly uses test scores to measure declarative knowledge and retention levels (Norman and Spohrer 1996; Sitzmann 2011). Concurrently, traditional tests are deemed inadequate to measure a broad range of higher-order thinking and problem-solving skills (Clarke and Dede 2010).

To evaluate higher order thinking skills, Burns et al. (1990) argue that identifying and developing clear learning objectives should guide the choice of the appropriate measurement or methodology. Learning objectives allow the instructor to define a desirable measurable outcome of what the learner will gain from the learning experience. Educational research has largely relied on Bloom's Taxonomy of educational objectives as a starting point in the development of assessment criteria (Bloom 1956; Cannon and Burns 1999). Bloom addresses three learning domains cognitive, affective, and psychomotor. For the cognitive domain, Bloom categorized learning objectives on a six-level scale (Figure 1), ranging from lower to higher order thinking skills (Anderson and Krathwohl 2001). Based on these levels, objectives are defined through a measurable verb, the condition in which the action is to happen, and a criterion for acceptable performance.

Using Bloom’s Taxonomy, Cannon and Burns (1999) developed a framework tailored for evaluating simulation games (Figure 2), which identifies learning objective as an essential step guiding the game design and performance criteria. The goal of this process, for the evaluator, is to identify performance behavior and requirements to meet the learning objectives. Based on this framework, Feinstein (2001) developed an assessment instrument for a food service simulation game containing a set of questions for each of the Bloom's six cognitive learning levels. The results of the study underlined the role of a simulation game in providing learners with higher order cognitive skills. Feinstein's example together with Cannon and Burn's framework, illustrate a path that the research team can leverage for the further development of the VCS game, discussed in the following section. 
Lower order thinking skills

\begin{tabular}{|c|c|c|c|c|c|}
\hline Remember & Understand & Apply & Analyze & Evaluate & Create \\
\hline $\begin{array}{l}\text { Recognizing } \\
\text { Identifying } \\
\text { Recalling }\end{array}$ & $\begin{array}{l}\text { Interpreting } \\
\text { Clarifying } \\
\text { Exemplifying } \\
\text { Illustrating } \\
\text { Classifying } \\
\text { Summarizing } \\
\text { Inferring } \\
\text { Comparing } \\
\text { Explaining }\end{array}$ & $\begin{array}{l}\text { Executing } \\
\text { Implementing }\end{array}$ & $\begin{array}{l}\text { Differentiating } \\
\text { Selecting } \\
\text { Organizing } \\
\text { Attributing }\end{array}$ & $\begin{array}{l}\text { Checking } \\
\text { Testing } \\
\text { Judging } \\
\text { Critiquing }\end{array}$ & $\begin{array}{l}\text { Hypothesizing } \\
\text { Planning } \\
\text { Producing }\end{array}$ \\
\hline
\end{tabular}

Figure 1. Categories of learning skills and cognitive processes (adapted from Heer 2009)

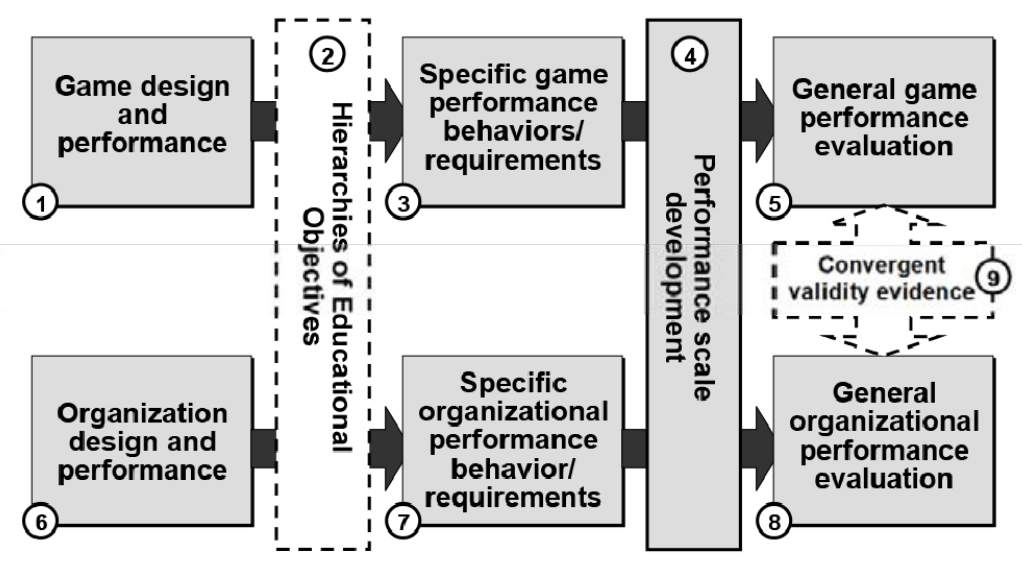

Figure 2. Based upon “A model for developing performance assessment criteria” (Cannon and Burns 1999)

\section{THE VIRTUAL CONSTRUCTION SIMULATOR 3: PAST EXPERIENCES}

The VCS3 is a simulation game that teaches students the dynamic nature of the construction process and frequent changes to construction schedules. The VCS3 allows the user to experiment with the planning and managing of construction schedules, while learning the difference between the as-planned and the as-built schedule (Nikolic 2011). The detailed development process of the simulation environment, together with development of the assessment instruments and results has been detailed in previous publications (Lee et al. 2011; Nikolic 2011). In short, the VCS3 was evaluated using both qualitative and quantitative methods, with preand post-test questionnaires. The VCS3 assessment was based on the Kirkpatrick's (2006) framework for evaluating training programs by looking at learners' reaction, learning, behavior and results.

The effectiveness of the VCS3 on student learning was measured through questions focusing on content knowledge and conceptual understanding. The assessment focused on students' ability to list, identify, and rank factors that affect the schedule (e.g. "List factors that affect construction activity duration"). Furthermore, students' ability to synthesize, summarize, and estimate possible 
schedule outcomes were also assessed through open and closed-ended questions. Additionally, learners' motivation was measured through the use of an adapted pre and post-test OnLine Motivation Questionnaires (Boekaerts 2002). The pre- and posttest items measured the task judgment (e.g. "How useful do you consider this exercise?"); the learning intent (e.g. "How well do you intend to perform on this exercise?"); and the emotional state (e.g. "How do you feel before starting the assignment?”, “nervous”, “fine”, “annoyed”, etc.). Lastly, the students' attitudes and reactions were gauged with a series of open-ended questions (e.g. "What would you change in the simulation game?”) and Likert scale questions. These questions provided the research team with suggestions for future game improvements.

The initial assessment results demonstrated the VCS3's ability to motivate the students and increase their general knowledge of construction planning processes (Nikolic 2011). However, while the VCS positively affected students' overall learning and motivation, the results still do not fully reveal the VCS3 simulator's ability to promote higher order thinking skills. The inherent challenge mainly lies in developing adequate assessment of those skills. While Kirkpatrick's training evaluation framework was used to evaluate the learner's lower order thinking skills, Cannon and Burns's model provides a framework for the evaluation of higher order of thinking skills tailored for simulations and games. The next phase of the VCS(4) development aims to address this challenge of assessing higher order thinking skills, by revisiting the game design and adopting additional assessment frameworks, beyond the one developed by Kirkpatrick (2006).

\section{LEARNING OBJECTIVES FOR THE VIRTUAL CONSTRUCTION SIMULATOR 4}

Based on previous results and feedback, the next VCS development and evaluation phase focuses on refining the simulation game development and assessment framework to address higher order thinking skills. The development of the framework will also inform the game's user interface development and educational assessment. The roadmap in Figure 3 illustrates the iterative nature of the VCS4 development, its learning objectives, user interface, system dynamics, and assessment methodology. Leveraging Cannon and Burns' (1999) framework, the team started with the review and development of specific learning objectives through identification of measurable verbs and conditions for the action to take place.

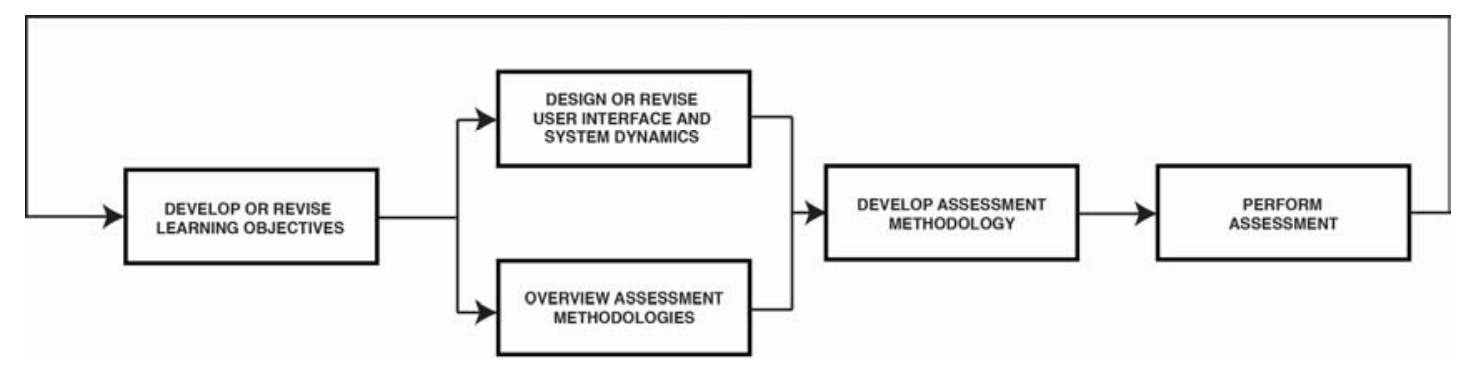

Figure 3. Roadmap for the VCS4 development and assessment

In this initial VCS4 development the team analyzed the previous learning objectives of the VCS3 simulation game (Figure 4). The goal of these learning 
objectives was to increase the knowledge in students about factors affecting the construction schedule, such as the choice of construction methods, resource planning and activity sequence. In addition to planning a schedule, the goal of the VCS3 was to teach students to actively manage resources and respond to changes to the schedule due to varying labor productivity and weather. However, even though these objectives were measured through appropriate assessment instruments, their development lacked the class instructors' input, and aimed to assess the lower and middle order thinking cognitive domains, knowledge and analysis.

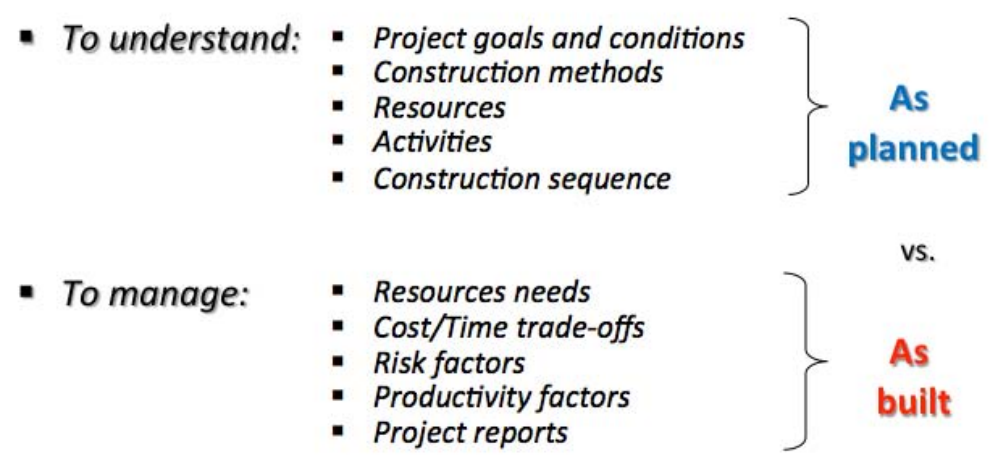

Figure 4. Initial learning objectives of VCS3

The learning objectives guiding the VCS4 game development are thus being synthesized from the objectives from two undergraduate construction engineering courses at the Penn State University - third year Introduction to the Building Industry and fourth year Building Construction Engineering. In the learning objectives for both example courses (Tables 1 and 2), action verbs pertaining to the construction planning and process are bolded. Based on Bloom's Taxonomy, action verbs such as identify, describe, provide, define, explain, and discuss, aim to measure the ability to remember and understand, are categorized as lower order thinking skills and are grayed out. Action verbs such as apply target middle order thinking skills. Meanwhile, verbs such as support, create, evaluate, and develop, aim to improve higher order thinking skills. Therefore, the courses' objectives focus on evaluating the student's ability to develop or create, evaluate, and support their decisions in the development of a schedule. The class assessment of the learning objectives for the third year course (Table 1) includes 3 class exams, several homework assignments, quizzes, and 3 project assignments. For the fourth year course, the listed objectives (Table 2) are assessed through 3 in-class exams, several homework assignments, review of 2 articles, a group project reviewing a construction site, and 2 individual construction process reviews. In both courses, participation is also accounted for as a metric for assessment. However, the research team has found that the courses do not use a platform that presents the students with real-time project constraints and allows them to test their assumptions. Hence, the students have to rely on the instructor's feedback on their schedule, which might come at a much later time from the initial schedule development. 


\section{Table 1. Learning Objectives for the Third Year "Introduction to the Building Industry" Class}

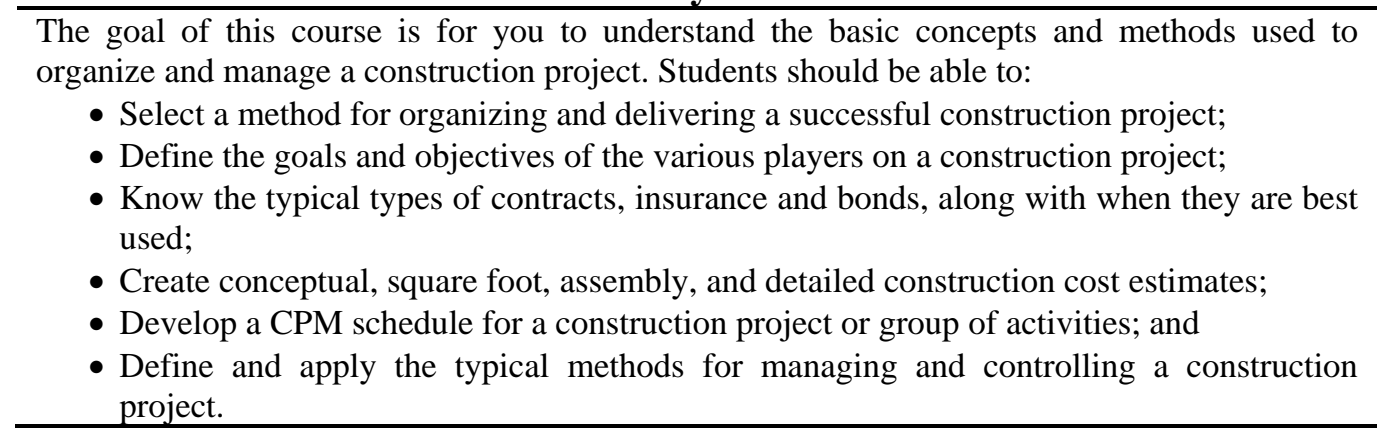

\section{Table 2. Learning Objectives for the Fourth Year "Building Construction} Engineering I" Class

At the completion of this course students will be able to:

- In a given situation, such as reviewing the design of a proposed project:

o Identify the construction methods for the building systems.

o Describe the method.

o Explain why the method is being used.

o Provide alternatives for the design.

- Use their knowledge of building materials and equipment, such as, concrete, steel, and masonry, to support their decision making on the related issues in different construction projects.

- Describe different construction procedures and details and identify the best one for a construction project.

- Develop and evaluate a project estimate and schedule using the tools for cost estimation and time scheduling.

- Identify project safety, productivity, and quality control concerns as they relate to the systems discussed in this course.

- Discuss current design and construction industry trends, issues, and events.

- Work in teams to strengthen communication and interpersonal skills for professional practice.

While these objectives allow for the assessment of lower and higher order thinking skills, the team aims for the enhancement of the latter through the use of a simulation game. Furthermore, the game provides the students with construction constraints and the ability to experiment and test for different outcomes. In collaboration with the course instructors, the revised set of learning objectives was developed (Table 3) to enhance both the courses' and the simulation objectives. The new set of learning objectives emphasizes the higher levels of Bloom's cognitive domains - creating, evaluating, and analyzing. For example, while the previous objectives addressed the describing and identifying of different construction procedures, the learner is now asked to determine the appropriate construction method. Additionally, the new objectives now seek the student's reflection and evaluation of the driving factors of the construction process, while the previous objectives only sought the identification of such factors. In addition to the courses' 
objective to assess the students' ability to support their decisions, the team will also assess their ability to compare and contrast planning considerations in the construction process. This objective will be supported with the addition of concrete and steel construction scenarios in the VCS4, where as VCS3 focuses on the construction of a pavilion. By identifying the action verbs and conditions in which each learning action is to happen, the team can then focus on the criteria to satisfy the objectives. Hence, these revised objectives will guide the next stage of the VCS4 user interface development and the selection of an assessment methodology for the cognitive learning process.

\section{Table 3. Learning Objectives for the VCS4}

At the completion of the VCS practicum exercise, student will be able to:

- Considering the construction methods, sequence and use of resources, develop and evaluate the optimum schedule that meets the project goal in the cost, time, safety, and efficient use of resources.

- Compare and contrast the planning considerations for constructing a steel and concrete structure given the same project scope.

- Evaluate and reflect on the driving factors and decisions during the construction process that affect construction progress and changes to the initial plan (as-planned vs. as-built).

- Given the project goal (budget, cost, safety); determine the appropriate construction methods based on their daily output and cost to develop a sequence.

- Identify factors that affect the labor productivity and explain how they affect the productivity

- Explain the driving factors affecting the efficient use of resources.

\section{CONCLUSIONS AND FUTURE RESEARCH}

Simulation and serious games have shown promise in promoting the motivation of learners. However, the assessment of the cognitive benefits of simulation games requires further analysis. In particular the assessment of higher order thinking skills would illustrate the capability of simulation games to advance the learning process. In order to evaluate such thinking skills, the learning objectives of the VCS3 simulation game were revisited and enhanced. With the development of the presented learning objectives the research team has taken the first step towards the formulation of a new game design and learning measurement methodology. Additionally, with this contribution the team hopes to provide future researchers with the learning objectives from which one can develop an assessment framework. Even though the evaluation has not been conducted, the presented work illustrates a necessary first step toward assessment of higher order thinking skills.

\section{ACKNOWLEDGMENTS}

We thank the National Science Foundation (Grant \#0935040) for support of the VCS3 game project. Any opinions, findings, conclusions, or recommendations 
expressed in this paper are those of the authors and do not necessarily reflect the views of the National Science Foundation.

\section{REFERENCES}

Anderson, L. W., and Krathwohl, D. R. (2001). A taxonomy for learning, teaching, and assessing: a revision of Bloom's taxonomy of educational objectives. Longman, New York.

Bloom, B. S. (1956). Taxonomy of educational objectives: the classification of educational goals Handbook I, Handbook I,. McKay ; Longman, New York; New York; London.

Boekaerts, M. (2002). "The On-line motivation questionnaire: A self-report instrument to assess students' context sensitivity." New directions in measures and methods, P. R. Pintrich and M. L. Maehr, eds., Emerald Group Publishing, 77-120.

Burns, A. C., Gentry, J. W., and Wolfe, J. (1990). "A cornucopia of considerations in evaluating the effectiveness of experiential pedagogies.” A guide to business gaming and experiential learning, J. W. Gentry, ed., East Brunswick, NJ/London: Nichols/GP., 253-278.

Cannon, H. M., and Burns, A. C. (1999). “A Framework For Assessing The Competencies Reflected In Simulation Performance.” Developments in Business Simulation \& Experiential Exercises, 26, 40-44.

Clarke, J., and Dede, C. (2010). “Assessment, technology, and change.” Journal of Research on Technology in Education, 42(3), 309-328.

Feinstein, A. H. (2001). "An Assessment of the Effectiveness of Simulation as an Instructional System in Foodservice.” Journal of Hospitality \& Tourism Research, 25(4), 421-443.

Feinstein, A. H., and Cannon, H. M. (2002). “Constructs of Simulation Evaluation.” Simulation \& Gaming, 33(4), 425-440.

Frand, J. L. (2000). "The Information-Age Mindset: Changes in Students and Implications for Higher Education.” EDUCASE Review (2000), 35(5).

Gee, J. P. (2007). "What video games have to teach us about learning and literacy." New York : Palgrave Macmillan, 2007.

Gosen, J., and Washbush, J. (2004). "A Review of Scholarship on Assessing Experiential Learning Effectiveness.” Simulation Gaming, 35(2), 270-293.

Heer, R. (2009). “A Model of Learning Objectives-based on A Taxonomy for Learning, Teaching, and Assessing: A Revision of Bloom's Taxonomy of Educational Objectives.” Center for Excellence in Learning and Teaching, Iowa State University.

Jonas-Dwyer, D., and Pospisil, R. (2004). "The Millennial effect: Implications for academic development.” Transforming Knowledge into Wisdom: Holistic Approaches to Teaching and Learning, HERDSA 2004 Conference Proceedings, 195-207.

Ke, F. (2009). “A Qualitative Meta-Analysis of Computer Games as Learning Tools.” Handbook of Research on Effective Electronic Gaming in Education. Information Science Reference, R. E. Ferdig, ed., Retrieved on August 2010 from: http://www.igi-global.com/downloads/excerpts/7960.pdf, 1-32. 
Kosslyn, S. M. (1994). Image and brain: The resolution of the imagery debate. Cambridge, MA: MIT Press.

Lattuca, L. R., Terenzini, P. T., Volkwein, J. F., and Peterson, G. D. (2006). “The Changing Face of Engineering Education.” The Bridge, 36(2).

Lee, S., Nikolic, D., Messner, J. I., and Anumba, C. J. (2011). “The Development of the Virtual Construction Simulator 3: An Interactive Simulation Environment for Construction Management Education.” American Society of Civil Engineers, 454-461.

Malone, T. W. (1981). “Toward a theory of intrinsically motivating instruction.” Congitive Science, 4, 333-369.

Mayer, R. E. (1998). "Cognitive, metacognitive, and motivational aspects of problem solving.” Instructional Science, 26, 49-63.

Mukherjee, A., Rojas, E. M., and Winn, W. D. (2005). "Interactive Situational Simulations in Construction Management." The First Conference on the Future of the AEC Industry.

Nguyen, T., Mondragon, F., O’Brien, W. J., and Schmidt, K. (2010). “Understanding our students: a technology and construction baseline survey." Computing in Civil and Building Engineering, Proceedings of the International Conference.

Nikolic, D., Lee, S., Messner, J. I., and Anumba, C. J. (2010). “The Virtual Construction Simulator - evaluating an educational simulation application for teaching construction management concepts." Proceedings of the 27th International Conference on Applications of IT in the AEC Industry, Cairo, Egypt.

Nikolic, D., and Messner, J. I. (2012). "Measuring the Value of 'All Play and No Work': Can the Rigorous Assessment of Simulation Games Drive Innovative Teaching in Construction?” Construction Research Congress 2012, American Society of Civil Engineers, 2101-2110.

Norman, D. A., and Spohrer, J. C. (1996). “Learner-Centered Education.” Communications of the ACM, 39(4).

O’Neil, H., Wainess, R., and Baker, E. (2005). “Classification of Learning OutcomesEvidence from the Computer Games Literature.” The Curriculum Journal, 16(4), 455-474.

Oblinger, D. (2003). "Boomers \& Gen-Xers, Millennials: Understanding the 'New Students'.” EDUCAUSE Review, 38(4).

Prensky, M. (2001). Digital Game-Based Learning. New York: McGraw-Hill.

Sitzmann, T. (2011). "A meta-analytic examination of the instructional effectiveness of computer-based simulation games.” Personnel Psychology, 64, 489-528.

Tener, R. K., Winstead, M. T., and Smaglik, E. J. (2001). "Experiential Learning from Internships in Construction Engineering."

Warren, D. V. (2001). "Design and Development of Simulation/Game Software: Implications for Higher Education.” The University Of British Columbia, Department of Educational Studies.

Wu, W., and Issa, R. (2013). "BIM Education and Recruiting: Survey-Based Comparative Analysis of Issues, Perceptions, and Collaboration Opportunities.” Journal of Professional Issues in Engineering Education and Practice, 0(0), 04013014. 